Epidemiology and Infection

cambridge.org/hyg

\section{Review}

Cite this article: Gomes Lima Santos N, Perez Pereira Ramos K, Shanmugam S, Oliveira de Carvalho F, Garcez Barreto Teixeira L, Ramos Silva É, de Vasconcelos Cerqueira-Braz J, Santos Nunes P, Antunes de Souza Araújo A (2018). New therapeutic patents used for the treatment of leprosy: a review. Epidemiology and Infection 146, 1746-1749. https://doi.org/ $10.1017 /$ S0950268818002145

Received: 9 March 2018

Revised: 24 May 2018

Accepted: 9 July 2018

First published online: 7 August 2018

\section{Key words:}

Hansen's disease; leprosy; Mycobacterium leprae; therapeutic compositions; treatment for leprosy

\section{Author for correspondence:}

Nayara Gomes Lima Santos, E-mail: nayaraa_gomes@hotmail.com

\title{
New therapeutic patents used for the treatment of leprosy: a review
}

\author{
Nayara Gomes Lima Santos ${ }^{1}$, Karen Perez Pereira Ramos ${ }^{1}$, \\ Saravanan Shanmugam ${ }^{1}$, Fernanda Oliveira de Carvalho ${ }^{1}$, Luciana Garcez \\ Barreto Teixeira ${ }^{1}$, Érika Ramos Silva ${ }^{1}$, Juliana de Vasconcelos Cerqueira-Braz ${ }^{1}$, \\ Paula Santos Nunes ${ }^{2}$ and Adriano Antunes de Souza Araújo ${ }^{3}$
}

${ }^{1}$ Postgraduate in Health Sciences. Federal University of Sergipe, UFS, Cláudio Batista s/n, Sanatorio, Aracaju, SE, Brazil; ${ }^{2}$ Department of Morphology, Federal University of Sergipe, UFS, Marechal Rondom Avenue s/n, São Cristóvão, SE, Brazil and ${ }^{3}$ Department of Pharmacy, Federal University of Sergipe, UFS, Marechal Rondom Avenue s/n, São Cristóvão, SE, Brazil

\begin{abstract}
Leprosy is a granulomatous disease, infectious and transmissible, which affects the skin and peripheral nerves, having Mycobacterium leprae as causative agent. The manifestation of this disease causes cutaneous lesions, peripheral neuropathies and, in more extreme cases, may generate deformities and disabilities in affected individuals. Patents were identified using the descriptor 'leprosy' and code A61K of the international patent classification, which indicates only products that meet human needs. The analysis was made using the WIPO, ESPACENET and USPTO databases, until the month of September 2016. Through this review, we found a variety of in vitro, pre-clinical and clinical studies relating to the treatment of leprosy with different types of compounds and forms of administration. New treatment proposals should include pain reduction capabilities, prevention or limitation of the appearance of cutaneous lesions, as well as prevention of the progression of the disease to more severe stages that may lead to loss of function or potentiate the individual's immune response to the $M$. leprae bacillus in order to prevent bacterial spread. We concluded that any patents developed with natural products were not found in the treatment of leprosy. All the deposited products were synthetic origin, mostly tested in humans and of varied forms of administration.
\end{abstract}

\section{Introduction}

Leprosy is a granulomatous disease, infectious and transmissible, which affects the skin and peripheral nerves, having $M$. leprae as causative agent [1]. The manifestation of this disease causes cutaneous lesions, peripheral neuropathies and, in more extreme cases, may generate deformities and disabilities in affected individuals [2].

The treatments recommended by the USA's National Leprosy Disease Programs and WHO points to a variation between dosage and duration of treatment, depending on the therapy type [3]. Those with uncertain diagnosis are treated as multibacillary leprosy [4].

During the course of the disease, reactions as neuralgia, loss of sensibility and function can rapidly lead severe and irreversible nerve damage and must be treated immediately upon an accurate diagnosis. Thus, new treatment proposals must provide pain reduction (especially those caused by nerve impairment), prevention or limitation of appearance of cutaneous lesions. Besides, new medicines should prevent disease progression to severe stages, which can lead to loss of function and potentialise the individual's immune response to M. leprae [5].

Standard multidrug therapy is highly effective in the treatment of $M$. leprae infection. However, despite this effectiveness, about $30-40 \%$ of patients with leprosy present inflammatory events caused by immunity, such as type I reactions and erythema nodosum leprosum (ENL) or type II reaction $[6,7]$. ENL is the most common inflammatory complication in leprosy patients. It is a systemic reaction, causing symptoms like arthritis, lymphadenitis and, especially, neuritis (the main cause of pain among these patients) [6].

If not treated, this inflammatory process caused by ENL significantly increases morbidity and mortality. The treatments with corticosteroids and thalidomide are the most widely used in clinical practice, for a long period of months or, even, years. In many patients, it is necessary to use high doses of corticosteroids to control ENL, resulting in complications associated with the prolonged use of drugs [7].

The increase in bacterial resistance against drugs used in conventional therapy has caused the emergence of antibacterial entities from a great number of natural sources, such as plant materials to fight microbial diseases [8].

Considering leprosy as a highly debilitating disease and of high therapeutic cost, there is the need of higher effectiveness treatment strategies that provide lower recurrence rate, toxicity and 
therapy duration. In this patents revision, we reported treatment systems and compounds proposed to treat Hansen disease. Therefore, this study has the objective of evaluating the development and patenting of natural and synthetic products, aimed to provide new therapeutic options for the treatment of leprosy and leprosy reactions.

\section{Methods}

The present study deals with a search for patents that bring possibilities of innovative treatments for leprosy. For this, the descriptor 'leprosy' and the code $\mathrm{A} 61 \mathrm{~K}$ of the international patent classification, which indicates only products that meet human needs, was used. The search was made using the WIPO, ESPACENET and USPTO databases, registered until the year 2016. The greatest number of patents was found in the WIPO database (250), followed by ESPACENET (149) with no patents being found in the USPTO database. The patents found were deposited in a period between 1920 and 2016.

All patents have been duly listed and classified according to the year of publication and country of origin. The USA and China were the countries with the largest number of patents, and the year with the largest number was 2015. Patents have been selected published between 2013 and 2016, because they expect to present the most recent products being developed for leprosy treatment. That is way, 341 patents were excluded. Subsequently, only texts written in English, Spanish or Portuguese were included in this review, resulting in 28 patents in other languages being excluded. Finally, titles and abstracts were read and duplicate patents (16), those without the full text available (two), and those not reporting treatment for leprosy (one) were also excluded, leaving nine remaining patents which were subjected to a complete reading of the text (Fig. 1).

\section{Results}

\section{Antibodies and peptides used in the treatment of leprosy}

Through this review, we found a variety of in vitro, pre-clinical and clinical studies relating to the treatment of leprosy (Tables 1 and 2). The first patent, described in 2013, is for a series of antibodies that are effective in the non-activation of trkA receptors, which enable control and prevention of painful conditions that affect the carriers of pathologies such as leprosy (NZ587701) [9].

Another patent from 2013 describes the use of 2-piperazin1-Yl-4H-1, 3-benzothiazin-4-oneas, a therapeutic and/or prophylactic treatment of infectious diseases (among them leprosy) in mammals, tested in rodents through an oral treatment (EP2640712) [10].

The first patent of 2014 is for a vaccine antigen to genes and proteins involved in the sporulation of mycobacteria. The vaccine induces an immune response against a peptide component from one of the gene products involved in sporulation and is indicated in the treatment of diseases caused by Mycobacterium, such as leprosy and tuberculosis (US8779088) [11].

Another registered patent relates to the treatment of diseases associated with the Th1 cascade and angiotensin II inhibitors. Through this mechanism, the authors believe that a range of diseases can be prevented or treated, these include leprosy, autoimmune diseases, type 1 and type 2 diabetes, rheumatic diseases (arthritis and rheumatoid arthritis), psoriasis, osteoporosis, atherosclerosis, myocarditis, endocarditis, pericarditis, Alzheimer's and cystic fibrosis, among others (US8865749) [12].

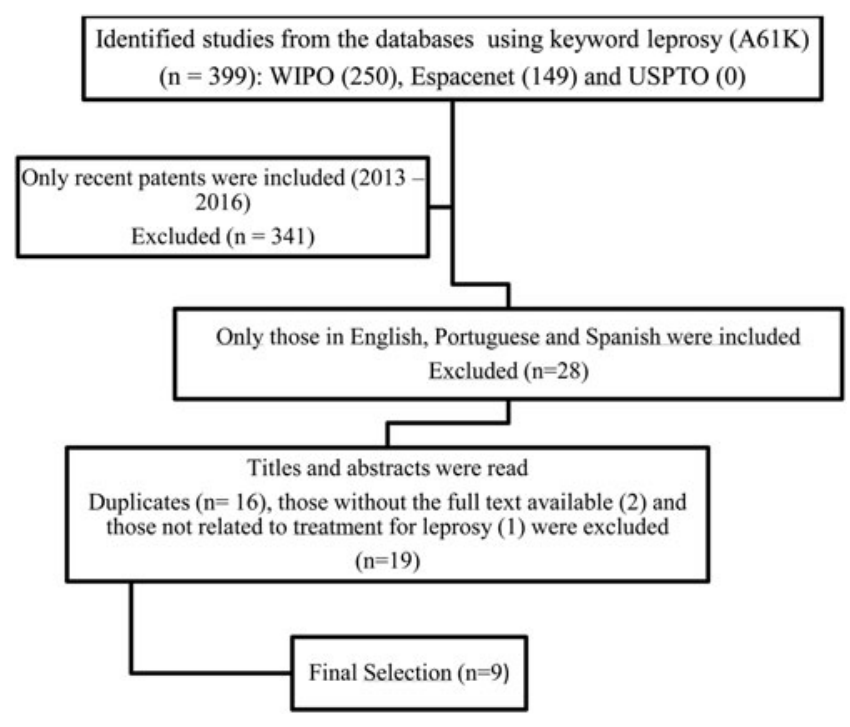

Fig. 1. Flowchart of studies included.

\section{Bioactive compounds in the treatment of leprosy}

A patent from 2015 describes the use of basic fuchsine, a nuclear dye used to identify the Mycobacterium tuberculosis, as an active ingredient of a drug to inhibit the acid-resistant bacillus in $M$. tuberculosis and $M$. leprae through increasing the $\mathrm{pH}$ of the individual, in the treatment against leprosy and tuberculosis. It can be administered orally, without need for hospitalisation (20150352063) [13].

Another invention published in 2015 proposed new compounds aiming to potentiate the antibiotic activity activated by the EthA pathway, in particular ethionamide, by inhibiting EthR. It aimed to develop an effective and inexpensive product with high solubility in fluids to be administered orally causing few side effects. Its use as a drug has been described for the treatment of bacterial and mycobacterial infections, tuberculosis and leprosy (US2015225388) [14].

A type of bioactive compound active in the inhibition of leucine kinase 2 protein (LRRK2) was described and patented in 2015 , through a study in vitro. According to the inventors, genetic studies have proven that LRRK2 acts in the pathogenesis of diseases such as Crohn's disease, leprosy, Parkinson's disease and other neurodegenerative diseases (CA2933767) [15].

Another patent describes the use of molecules (4-(substituted amino)-7H-pyrrolo (2,3-d) pyrimidines) to inhibit repetitions rich in leucine kinase 2 (LRRK2), as a form of treatment for diseases such as leprosy and neurodegenerative disorders, because they are diseases associated with LRRK2 (20140005183) [16].

In another invention in 2015, the researchers developed a pharmaceutical compound containing thalidomide and other bioavailable and easily manufactured components that are already approved for use in humans. Thalidomide acts in the treatment of erythema, dermal wounds and inflammation in the gut, among other diseases, and according to the inventors, it is effective in the treatment of wounds caused by leprosy (US9006267) [17].

\section{Discussion}

According to this study, no patents were found that use a product of natural origin as an active ingredient, or that directly treated 
Table 1. Antibodies and peptides used in the treatment of leprosy

\begin{tabular}{|c|c|c|c|c|c|c|}
\hline Patent title & Year & Country & $\begin{array}{l}\text { Patent } \\
\text { number }\end{array}$ & $\begin{array}{l}\text { Experimental } \\
\text { stage }\end{array}$ & Active principle & $\begin{array}{l}\text { Natural or } \\
\text { synthetic }\end{array}$ \\
\hline Anti-TrkA antibodies and derivatives thereof & 2013 & NZ & NZ587701 & Clinical & Anti-TrkA antibodies & Synthetic \\
\hline $\begin{array}{l}\text { 2-Piperazin-1-yl-4h-1,3-benzothiazin-4-one derivatives and } \\
\text { their use for the treatment of mammalian infections }\end{array}$ & 2013 & EP & 2640712 & Preclinical & $\begin{array}{l}\text { 2-Piperazin-1-il-4H-1, } \\
\text { 3-benzothiazin-4-one }\end{array}$ & Synthetic \\
\hline $\begin{array}{l}\text { New vaccine for the treatment of Mycobacterium-related } \\
\text { disorders }\end{array}$ & 2014 & USA & US8779088 & - & Vaccines and antibodies & Synthetic \\
\hline $\begin{array}{l}\text { Treatment and prevention of th } 1 \text { and 'autoimmune' diseases } \\
\text { with antibiotics and/or angiotensin inhibition }\end{array}$ & 2014 & USA & US8865749 & - & Antibiotics & Synthetic \\
\hline
\end{tabular}

Table 2. Bioactive compounds in the treatment of leprosy

\begin{tabular}{|c|c|c|c|c|c|c|}
\hline Patent title & Year & Country & $\begin{array}{l}\text { Patent } \\
\text { number }\end{array}$ & $\begin{array}{l}\text { Experimental } \\
\text { stage }\end{array}$ & Active principle & $\begin{array}{l}\text { Natural or } \\
\text { synthetic }\end{array}$ \\
\hline Drug for killing acid-fast (red) bacillus & 2015 & USA & 20150352063 & Clinical & Basic fuchsine & Synthetic \\
\hline $\begin{array}{l}\text { Compounds for use in the treatment of } \\
\text { mycobacterial infections }\end{array}$ & 2015 & USA & US2015225388 & In vitro & EthA & Synthetic \\
\hline $\begin{array}{l}\text { Novel 3,4-disubstituted-1h-pyrrolo(2,3-b) pyridines } \\
\text { and 4,5-disubstituted-7h-pyrrolo (2,3-c) pyridazines } \\
\text { as Irrk2 inhibitors }\end{array}$ & 2015 & $\mathrm{CA}$ & CA2933767 & In vitro & LRRK2 & Synthetic \\
\hline $\begin{array}{l}\text { 4-(substituted amino)-7H-pyrrolo(2,3-d) } \\
\text { pyrimidines as LRRK2 inhibitors }\end{array}$ & 2014 & USA & 20140005183 & Preclinical & $\begin{array}{l}\text { 4-(amino-substituted)-7H-pyrrolo } \\
\text { (2,3-d) pyrimidine }\end{array}$ & Synthetic \\
\hline $\begin{array}{l}\text { Pharmaceutical compositions and dosage forms of } \\
\text { thalidomide }\end{array}$ & 2015 & USA & US9006267 & Clinical & Thalidomide & Synthetic \\
\hline
\end{tabular}

the causative agent of $M$. leprae disease. The course of treatment for leprosy is long and commonly used drugs include rifampicin, chlorophenol diazoxide, sulfamide, which are highly toxic and can cause serious damage to the liver, kidney, nervous system, gastrointestinal tract and haematopoietic organs. Therefore, one of the emergency needs currently is the search for a shorter therapy duration, as well as the use of antibacterial agents with minimal toxic effects for leprosy patients [18].

Bioactive products have great benefits in treating the disease, including low toxicity when compared with other drugs; low cost, which reduces the financial burden for individuals and health systems; and easy availability, many are found in common products such as rice, wheat germ or cereals; in addition to not having recurrence of symptoms and not having adverse reactions [18].

The infection caused by $M$. leprae triggers a relationship between the pathogens and the host, based mainly on immune pathological aspects [19]. Thus, leprosy is an interesting model to investigate the role of the human immune system in the defence of the host and susceptibility to infection [20].

Infections caused by mycobacteria are notoriously difficult to treat. Although most mycobacteria are susceptible to antibiotics such as clarithromycin, isoniazid and rifamycin, antibiotic-resistant strains exist, and the emergence of multiresistant strains is an increasing problem. One of the causes of bacterial resistance is the abandonment of the treatment, due to its long duration, leading to the interruption of the therapy, thus contributing to the resistance of M. leprae [21].

Toll-like receptors are crucial for the recognition of microorganisms by macrophages and dendritic cells during the innate immune response [22]. These receptors stimulate the production of antimicrobial peptides, cytokines such as interleukin (IL)- $1 \beta$,
IL-6, tumour necrosis factor $\alpha$ and chemokines that collectively induce a local inflammatory response, and increase phagocytosis and death mediated by activated macrophages [23].

The treatment involves identifying an antibody-reactive compound for a spore-coating peptide or an active fragment, leading to the induction of the immune response in the patient [24]. These recent studies are based on an active immunisation, performed by administering a vaccine or passively with the use of an antibody [24]. Although current treatments of leprosy found in this review are based on the use of antibiotics and drugs or vaccines containing antibodies, the use of natural active principles has grown exponentially throughout the world and their efficacy has been verified in the treatment of numerous diseases [19].

Besides the search for strategies that decrease treatment duration and avoid occurrence of antibiotic resistance, current researches are focused on the development of more effective diagnosis for the detection of infections in early stages of the disease, enabling prophylactic and adequate treatment. It is expected that vaccines develop active and long-term protection, both in the prevention of infection and of disease or recurrences $[25,26]$.

Over the researches on leprosy and its reactions, many difficulties are found, mainly those related to the development of new short-term therapeutics, because of the heterogeneity of the disease's clinical forms and the immunological response of the host to the agent [27]. In this review, only three patents found were in clinical development, being that one patent brings thalidomide as main compound, this being considered of alternative use by the WHO. The other two patents, from 2013 and 2015, were in clinical trials, testing new products. Thus, we could observe the need for patents filed being in clinical trials and the 
low number of new products resulting from these patents. Therefore, it is necessary to develop translational researches (preclinical trials up to clinical trials in its final steps) focusing on the development of a new patented product with the perspective of marketing by the pharmaceutical industry.

\section{Conclusion}

In this review, we concluded that any patents developed with natural products were not found in the treatment of leprosy. All the deposited products were synthetic origin, mostly tested in humans and of varied forms of administration. Therefore, it is necessary to concentrate this research area with the aim to reduce the effect of leprosy on individuals, and to develop a promising new products or drugs that provide preventing disease progression accompanying with analgesic as well as effective healing property.

Acknowledgements. The authors would like to thank the Conselho Nacional de Desenvolvimento Científico e Tecnológico/CNPq/Brazil and Fundação de Amparo à Pesquisa do Estado de Sergipe/FAPITEC-SE for financial support in the postgraduate scholarships.

Conflict of interest. None.

\section{References}

1. Lockwood DNJ (2004) Leprosy. In Burns DA, Breathnach SM, Cox NH and Griffiths CEM (eds), Rook's Textbook of Dermatology, 7th Edn. Oxford: Blackwell Publishing, pp. 29.21-29.21.

2. WHO - Global leprosy situation (2009) Weekly Epidemiological Record. 84, pp. 333-340.

3. Sanford CA, Pottinger PS and Jong EC (2017) The Travel and Tropical Medicine Manual. 5th edn. USA. Chapter 40 - Leprosy (Hansen's Disease). pp. 513-523.

4. WHO Model prescribing information (1998) Drugs Used in Leprosy. Treatment of Leprosy. Geneva: World Health Organization.

5. Haanpaa M, Lockwood DNJ and Hietaharju A (2004) Neuropathic pain in leprosy. Leprosy Review 75, 7-18.

6. Polycarpou A, Walker SL and Lockwood DNJ (2017) A systematic review of immunological studies of erythema nodosum leprosum. Frontiers in Immunology 8, 233.

7. Walker SL et al. (2015) ENLIST 1: an international multi-centre crosssectional study of the clinical features of erythema nodosum leprosum. PLoS Neglected Tropical Diseases 9, e0004065.

8. Bakkali F et al. (2008) Biological effects of essential oils - a review. Food and Chemical Toxicology 46, 446-475.

9. Benigni $\mathbf{F}$ and D'ambrosio D Anti-trka antibodies and derivatives thereof, 2013 (NZ587701). Antibodies that ensures control and prevention of painful conditions affecting leprosy patients.

10. Stewart MVC 2-Piperazin-1-Yl-4h-1,3-benzothiazin-4-one derivatives and their use for the treatment of mammalian infections. (EP2640712).
Therapeutic and/or prophylactic treatment of infectious diseases (including leprosy) in mammals.

11. Leif K, Santanu D and Pontus L New vaccine for the treatment of Mycobacterium related disorders. (US8779088). Vaccine indicated for the treatment of diseases caused by Mycobacterium.

12. Marshall TG Treatment and prevention of thl and 'autoimmune' diseases effected with antibiotics and/or angiotensin inhibition. (US8865749). Invention which aims to eliminate intracellular bacteria that cause Th1 and 'autoimmune' diseases.

13. Shuxian HU et al. Drug for killing acid-fast (red) bacillus. (20150352063). Acid-resistant inhibitor drug to bacillus in the Mycobacterium tuberculosis and Mycobacterium leprae.

14. Willand $\mathrm{N}$ et al. Compounds for use in the treatment of mycobacterial infections. (US2015225388). Treatment of bacterial and mycobacterial infections by potential antibiotic activity.

15. Galatsis $\mathbf{P}$ et al. Novel 3,4-disubstituted-1h-pyrrolo[2,3-b] pyridines and 4,5-disubstituted-7h-pyrrolo [2,3-c] pyridazines as lrrk2 inhibitors. (CA2933767). A type of bioactive compound active in the inhibition of leucine kinase 2 protein.

16. Galatsis $\mathbf{P}$ et al. 4-(Substituted amino)-7H-pyrrolo[2,3-d] pyrimidines as LRRK2 inhibitors. (20140005183). Treatment of diseases such as leprosy, and neurodegenerative disorders.

17. Angio PD and Mccarty $J$ Pharmaceutical compositions and dosage forms of thalidomide. (US9006267). An effective pharmaceutical compound in the treatment of wounds caused by leprosy.

18. Shuxian HU et al. Drug for killing acid-fast (red) bacillus. (US20150352063A1) 2015.

19. Teles RMB et al. (2010) Interleukin-4 regulates the expression of CD209 and subsequent uptake of Mycobacterium leprae by Schwann cells in human leprosy. Infection and Immunity 78, 4634-4643.

20. Dionello CF et al. (2015) Evaluation of rheumatoid factor and anticitrullinated peptide antibodies in relation to rheumatological manifestations in patients with leprosy from Southern Brazil. International Journal of Rheumatic Diseases 19, 1024-1031.

21. De Sousa J et al. (2017) Endothelium adhesion molecules ICAM-1, ICAM-2, VCAM-1 and VLA-4 expression in leprosy. Microbial Pathogenesis 104, 116-124.

22. Beutler BA (2009) TLRs and innate immunity. Blood 113, 1399-1407.

23. O'neill LAJ and Hardie DG (2013) Metabolism of inflammation limited by AMPK and pseudo-starvation. Nature 493, 346-355.

24. Kirsebom L $\boldsymbol{e t}$ al. Vaccine for the treatment of Mycobacterium related disorders. U.S. Patent Application No. 14/288,861.

25. Regional Office for South-East Asia, World Health Organization (2016) Global Leprosy Strategy 2016-2020: Accelerating Towards a Leprosy-Free World. WHO Regional Office for South-East Asia. Available at http:// www.who.int/iris/handle/10665/208824

26. World Health Organization (2015) Implementing the End TB Strategy: The Essentials. World Health Organization. Available at http://www. who.int/iris/handle/10665/206499

27. Ridley DS and Jopling WH (1966) Classification of leprosy according to immunity. A five-group system. International Journal of Leprosy and Other Mycobacterial Diseases 34, 255-273. 